\title{
Association between social capital and frailty and the mediating effect of health-promoting lifestyles in Chinese older adults: a cross- sectional study
}

\author{
Shan $\mathrm{Hu}^{1}$, Canhuan $\mathrm{Jin}^{1}$ and Shaojie $\mathrm{Li}^{2^{*}}$
}

\begin{abstract}
Background: To explore the association between social capital and frailty and the mediating effect of health-promoting lifestyles among Chinese older adults, while providing scientific evidence for frailty intervention.

Methods: In May 2021, a cross-sectional study was conducted among 674 Chinese older adults in Changsha city. Data was collected using the Chinese Shortened Social Capital Scale (comprising structural social capital and cognitive social capital as two subscales), a simplified version of the Health-Promoting Lifestyle Profile and the Tilburg Frailty Indicator. Linear regression analysis was used to examine the association between social capital and frailty. Structural equation modeling was used to test the mediating effect of health-promoting lifestyles.

Results: Cognitive social capital was significantly negatively associated with frailty and its three dimensions (physical, psychological, and social frailty), but structural social capital was not. Health-promoting lifestyles played a mediating role in the associations of cognitive social capital with frailty, physical and psychological frailty, but not with social frailty.

Conclusions: Higher cognitive social capital was associated with a reduced likelihood of frailty. The health-promoting lifestyles partially mediated the association between cognitive social capital and frailty. The use of health-promoting lifestyles or appropriate cognitive social capital interventions may reduce frailty among older adults.
\end{abstract}

Keywords: Social capital, Health-promoting lifestyles, Frailty, Older adults

\section{Background}

The aging of a population is a major social problem worldwide, affecting all aspects of the economy, politics, social development, and the health care system [1]. In the field of public health, the prevention of aging-related diseases (including cognitive impairment, disability, frailty, etc.) is a trending topic. Among them, as a disease

\footnotetext{
*Correspondence: ii10233972@163.com

${ }^{2}$ Department of Social Medicine and Health Service Management,

Xiangya School of Public Health, Central South University,

Changsha 410078, China

Full list of author information is available at the end of the article
}

syndrome closely related to age, frailty has become an important criterion for the evaluation of the health status of older adults [2]. The core feature of frailty is the decline in the physiological capacity of multiple organ systems, leading to increased susceptibility to stressors [3]. Metaanalysis results have indicated that frailty increases the risk of a series of negative health outcomes [4], such as mortality [5], hospitalization [6], disability [7], falls [8], fractures [9], and dementia [10]. In recent years, with the increase in the aging population, the incidence and prevalence of frailty has also been increasing. The results of a systematic review indicated that among non-frail 
individuals with a median follow-up time of 3 years, the combined incidence of frailty was 43.4 per thousand person-years [11]. A meta-analysis of older adults in communities in low-income and middle-income countries revealed that the combined prevalence of frailty was $17.4 \%$, and the prevalence of prefrailty was $49.3 \%$ [12]. Considering the negative health status caused by the high incidence and prevalence of frailty and related factors, should be explored to provide scientific evidence for the prevention of, and intervention for, frailty in older adults.

The mechanism of the occurrence and development of frailty is more complicated, and is the result of the interaction of many factors. At present, a considerable number of studies have explored the factors related to frailty in older adults. A literature review revealed that sociodemographic factors (such as sex, age, education level, and income) [13], physiological factors (such as genes, inflammatory factors, body composition, and malnutrition) [14-17], chronic diseases (such as diabetes, cardiovascular disease, and stroke) [18], lifestyles (such as physical activity, sedentary lifestyle, fruit and vegetable consumption, and dietary patterns) [19-21] and psychological factors (such as stress, depression, and anxiety) [22-24] may cause frailty. In addition, studies have also found that social factors such as social isolation [25], frequency of interaction with relatives and friends [26], and social support [27] were associated with frailty. However, the social factors in these studies were predominantly examined at individual level, and few studies investigated the association between overall social factors, such as social capital, and frailty $[28,29]$.

Social capital refers to the social resources and benefits that individuals obtained through contact with others [30], and are usually divided into two aspects: Structural social capital and cognitive social capital [31]. The structural aspect refers to externally observable social resources, such as social networks and social participation, and the cognitive aspect reflects the subjective attitude and evaluation of social relations, such as trust and the norms of reciprocity [31]. Social capital is considered to be a positive social determinant of health [32], and a large number of studies have confirmed that it is significantly related to physical and mental health [33, 34]. In addition, increased evidence indicates that interventions related to social capital can significantly improve the health of older adults and promote healthy aging [35]. A previous review emphasized the need to investigate the impact of social capital on frailty in older adults in the context of the rapid growth in global life expectancy and aging [36]. However, there is limited empirical research exploring the relationship between social capital and frailty in older adults. Previous studies on the frailty and aging cohort in Korea have indicated that insufficient social capital is significantly related to frailty [28]. However, the study defined insufficient social capital as a lack of participation in social gatherings [28], and Japanese research on frailty factors only reflected social capital from three aspects: social participation in activities, trust in the community, and interaction with neighbors [29]. These definitions and assessment contents were evidently one-sided and failed to reflect the true meaning of social capital. Therefore, it is necessary to adopt more comprehensive social capital assessment tools to better explore its association with frailty.

In addition, to better prevent and intervene with regard to frailty in older adults from the social capital perspective, the potential mediating factors in the relationship between to social capital and frailty should be understood. The model of the social determinants of health maintains that personal health is primarily affected by four aspects, namely, 1) general social factors, such as social economy, culture, and environment, 2) living and working conditions, 3) community network, and 4) personal lifestyles [37]. Among them, social factors are considered to be upstream determinants, that can have an indirect impact on individual health through downstream lifestyle factors [38]. Previous studies have found that social capital can indirectly affect health through lifestyles [39]. However, it remains unknown whether the mediating role of healthy lifestyles can be generalized to the relationship between social capital and frailty. Considering that lifestyles are significantly related to social capital and frailty [40, 41], the above-mentioned mediation effect may also be established, but there is no research to confirm it.

Therefore, the objective of this study was to investigate the association between social capital (including structural and cognitive social capital) and frailty (including physical, psychological, and social frailty) of older adults. We also explored the potential mediating role of healthpromoting lifestyles in the association between social capital and frailty. We developed the following priori hypotheses: 1) Social capital will be positively correlated with frailty; 2) Health-promoting lifestyles will mediate the relationship between social capital and frailty.

\section{Methods \\ Participants}

The formula for an epidemiologic study for estimating population rate $\left(n=\frac{Z_{\alpha / 2}{ }^{2} \pi(1-\pi)}{\delta^{2}}\right)$ was used to calculate sample size [42]. According to a previous systematic review, the prevalence of frailty in the older adult population in China was $12.8 \%$ [43]. Thus, we set $\pi$ as 0.128 in this study. If $\alpha$ was $0.05, Z_{\alpha / 2}$ was 1.96 , and $\delta$ was 0.15 , the calculated sample size was 476 . To prevent an invalid 
survey sample, we increased the sample by $20 \%$, which made the minimum sample size in the survey 571 . The stratified cluster sampling method was used for sample selection. In May 2021, three districts or counties were randomly selected from six districts and three counties in Changsha City. Consequently, we randomly selected two communities from the three districts or counties, respectively, and surveyed all the older adults in these six communities. The inclusion criteria for the participants were: age greater than or equal to 60 years; local household registration; voluntary participation in the survey. The exclusion criteria were: suffering from serious physical and psychological diseases (reported by family members, such as schizophrenia, dementia, and depression); hearing and vision impairments. University students who had undergone uniform survey training conducted face-toface interviews with the participants.

\section{Measures}

The questionnaire contained questions regarding demographic characteristics, social capital, health-promoting lifestyles, and frailty. No one of the questionnaires or scales used in our study require a license in order to administer them.

\section{Chinese shortened social capital scale (CSSCS)}

The CSSCS, which is widely used to assess the social capital of Chinese older adults [40,44, 45], is a 22-item 5-point Likert (ranging from $1=$ "very inconsistent" to $5=$ "very consistent) scoring scale. The scale includes two subscales of structural social capital (11 items, comprising three dimensions: social participation, social support, and social connection) and cognitive social capital (11 items, comprising three dimensions: trust, cohesion, and reciprocity). The sum of all items is the total score. The higher the score, the greater social capital of the participant. The overall Cronbach's $\alpha$ coefficient of CSSCS is 0.92 , and it has high construct validity [45].

\section{Simplified version of the health-promoting lifestyle profile (HPLP-S)}

The HPLP-S is a 24-item scale comprising six dimensions (included four items, respectively): self-actualization, health responsibility, exercise, nutrition, interpersonal support, and stress management. The scale is a simplified version of the 48-item HPLP [46, 47], and each item is scored on a scale of $1=$ "never" to $4=$ "always." The total score is calculated by summing the scores of 24 items, and ranges from 24 to 96 points. The higher the total score, the healthier the lifestyle. The Cronbach's $\alpha$ coefficient of HPLP-S is 0.90 , and it demonstrates good construct validity [48].

\section{Tilburg frailty Indicator (TFI)}

The TFI, which is widely used to assess the frailty in community-dwelling older adults [49], is a 15-item scale comprising three dimensions: physical (eight items), psychological (four items), and social frailty (three items). Each item is scored across two categories [50], that is, "No" is assigned 0 points, and "Yes" is assigned 1 point. The sum of 15 items is the total score of the TFI, and ranges from 0 to 15 points. The higher the score, the more severe the participant's frailty. A total score greater than or equal to 5 indicates participant frailty. In this study, we used the Chinese version of the TFI, which has been verified among older adults in the community, and has good reliability (Cronbach's $\alpha$ is 0.71 and test-retest reliability is 0.88 ) and validity (criterion validity with the Area Under Curves regarding physical phenotype and a frailty index of 0.87 and 0.86 ) [51].

\section{Demographic factors}

A self-designed demographic information questionnaire (Additional file 1) was used to collect data on participants' age (60-69, 70-79, and $\geq 80$ years), sex, residence (urban or rural), education level (primary school and below, junior middle school, high school, university and above), marital status (unmarried or married), monthly family income $(<5000,5000-10,000,>10,000)$, and selfrated health (poor, moderate, good).

\section{Data analysis}

Continuous variables conforming to normal distribution (such as social capital, health-promoting lifestyle, and frailty) were described by means \pm standard deviation (SD), and categorical variables (such as sex, residence, etc.) were described by $\mathrm{N}(\%)$. Pearson's correlation was used to analyze the relationship between social capital, health-promoting lifestyles, and frailty. Linear regression was used to analyze the associations between social capital and frailty and the three dimensions of frailty after adjusting for demographic factors. The above analysis was all conducted using SPSS version 25 (IBM SPSS Statistics, Armonk, NY, USA).

The hypothesized mediation model (Fig. 1) test used Amos 24.0 to construct structural equation models (SEM) with bootstrap methods with 95\% confidence interval (CI) estimation based on bias correction. The principle of mediation analysis and relevant guidelines indicated that the total, direct and indirect effect were all significant $[52,53]$. First, in this study, the path from social capital to frailty (path c, Fig. 1) was significant; second, the path from social capital to health-promoting lifestyles (path a) was significant; third, controlling for social capital, the path from health-promoting lifestyles 


\begin{tabular}{|c|c|}
\hline $\begin{array}{c}\text { Social capital / Structural } \\
\text { social capital / } \\
\text { Cognitive social capital }\end{array}$ & Path c \\
\cline { 2 - 4 }
\end{tabular}

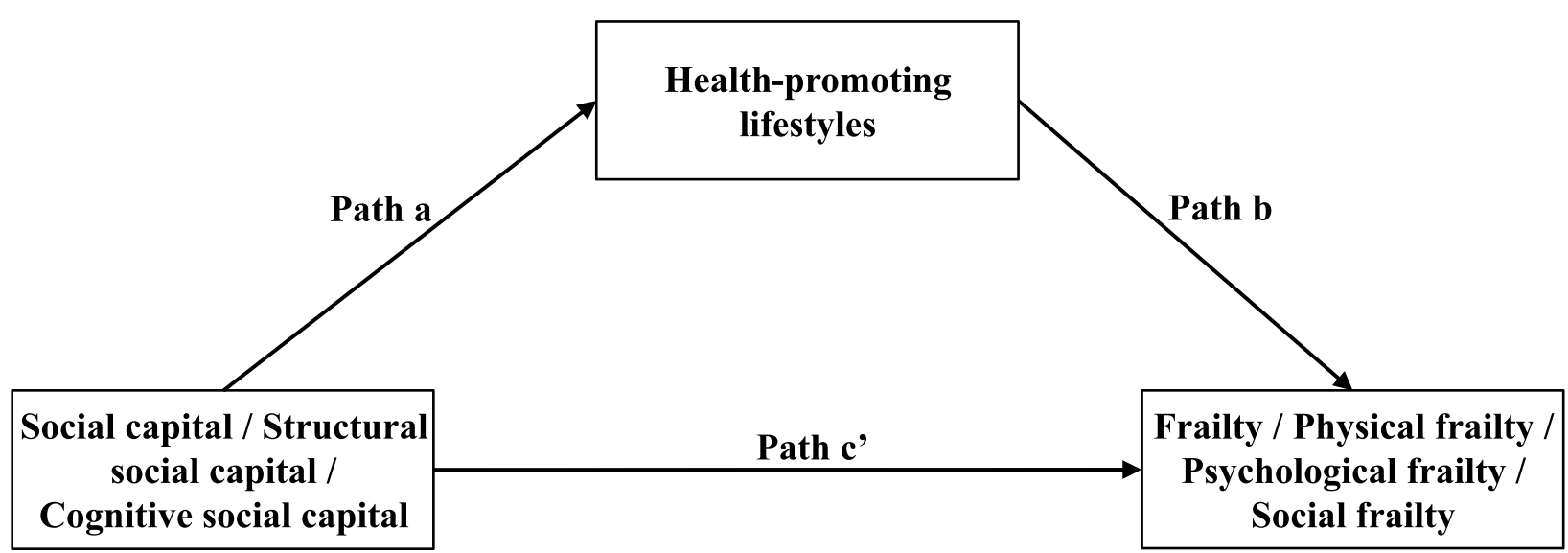

Fig. 1 The hypothesised model

to frailty (path b) was also significant; and finally, the indirect effect of health-promoting lifestyles $\left(\mathrm{a}^{*} \mathrm{~b}\right)$ in the association between social capital and frailty was significant (the 95\% CI did not include 0).

\section{Results}

\section{Descriptive statistics}

Descriptive analysis and differences in social capital, health-promoting lifestyles, and frailty scores among participants with different demographic characteristics are illustrated in Table 1.

\section{Correlations between social capital, health-promoting lifestyles, and frailty}

Pearson's $r$ correlation analysis indicated that social capital as well as structural and cognitive social capital were all significantly positively associated with health-promoting lifestyles, and were significantly negatively associated with frailty and its three dimensions. Moreover, healthpromoting lifestyles were also significantly negatively associated with frailty and its three dimensions (Table 2).

\section{Linear regression analysis for the association between social capital and frailty}

The results of the linear regression analysis indicated that the associations between structural social capital and frailty and its three dimensions was not statistically significant after adjusting for demographic factors.
However, cognitive social capital was significantly negatively associated with frailty and its three dimensions. The details of all linear regression results are shown in Table 3.

\section{Mediation test for health-promoting lifestyles}

We constructed four models to test the mediating role of health-promoting lifestyles in the associations between cognitive social capital and frailty and its three dimensions (Fig. 2, Table 4). Health-promoting lifestyles played a mediating role in the associations between cognitive social capital and frailty, as well as the physical and psychological frailty dimensions, but not social frailty.

\section{Discussion}

This study examined the relationship between social capital and frailty in older adults, and explored the mediating effect of health-promoting lifestyles in this relationship. The results showed that cognitive social capital was significantly negatively associated with frailty and its three dimensions (physical, psychological, and social frailty), but structural social capital was not. In addition, healthpromoting lifestyles played a mediating role in the associations between cognitive social capital and frailty, as well as the physical and psychological frailty dimensions, but not social frailty.

Our results indicated that after controlling for demographic factors, cognitive social capital was significantly 
Table 1 Descriptive analysis and differences in social capital, health-promoting lifestyles, and frailty scores among participants with different demographic characteristics $(N=674)$

\begin{tabular}{|c|c|c|c|c|c|c|}
\hline \multirow[t]{2}{*}{ Characteristics } & \multirow[t]{2}{*}{$N(\%)$} & \multicolumn{5}{|l|}{ Mean \pm SD } \\
\hline & & Social capital & Structural social capital & Cognitive social capital & $\begin{array}{l}\text { Health } \\
\text {-promoting lifestyles }\end{array}$ & Frailty \\
\hline \multicolumn{7}{|l|}{ Age (years) } \\
\hline $60-69$ & $347(51.5)$ & $74.66 \pm 12.48$ & $32.58 \pm 6.61$ & $42.08 \pm 7.89$ & $63.59 \pm 12.13$ & $2.98 \pm 2.02$ \\
\hline $70-79$ & $270(40.1)$ & $74.87 \pm 13.59$ & $32.52 \pm 6.98$ & $42.35 \pm 8.62$ & $64.77 \pm 13.01$ & $3.56 \pm 2.53$ \\
\hline$\geq 80$ & $57(8.5)$ & $72.46 \pm 18.72$ & $32.56 \pm 10.79$ & $39.89 \pm 10.24$ & $63.98 \pm 16.71$ & $4.53 \pm 2.80$ \\
\hline \multicolumn{7}{|l|}{ Sex } \\
\hline Male & $341(50.6)$ & $74.24 \pm 13.25$ & $32.59 \pm 7.20$ & $41.65 \pm 8.16$ & $63.12 \pm 12.69$ & $3.46 \pm 2.38$ \\
\hline Female & $333(49.4)$ & $74.88 \pm 13.86$ & $32.52 \pm 7.18$ & $42.37 \pm 8.66$ & $65.10 \pm 13.10$ & $3.23 \pm 2.30$ \\
\hline \multicolumn{7}{|l|}{ Residence } \\
\hline Urban area & $285(42.3)$ & $73.84 \pm 13.90$ & $32.32 \pm 7.38$ & $41.52 \pm 8.81$ & $64.48 \pm 13.58$ & $4.18 \pm 2.70$ \\
\hline Rural area & $389(57.7)$ & $75.08 \pm 13.28$ & $32.72 \pm 7.04$ & $42.36 \pm 8.11$ & $63.82 \pm 12.42$ & $2.73 \pm 1.82$ \\
\hline \multicolumn{7}{|l|}{ Education level } \\
\hline Primary school and below & $394(58.5)$ & $73.66 \pm 13.66$ & $32.00 \pm 6.90$ & $41.66 \pm 8.54$ & $62.64 \pm 12.18$ & $3.51 \pm 2.46$ \\
\hline Junior middle school & $176(26.1)$ & $74.74 \pm 12.36$ & $32.78 \pm 6.58$ & $41.97 \pm 8.07$ & $63.69 \pm 11.65$ & $3.02 \pm 1.97$ \\
\hline High school & $82(12.2)$ & $76.74 \pm 13.21$ & $33.57 \pm 7.97$ & $43.17 \pm 8.13$ & $68.89 \pm 16.23$ & $3.22 \pm 2.48$ \\
\hline University and above & $22(3.3)$ & $81.05 \pm 19.20$ & $36.86 \pm 11.31$ & $44.18 \pm 9.74$ & $75.64 \pm 12.37$ & $3.41 \pm 2.28$ \\
\hline \multicolumn{7}{|l|}{ Marital status } \\
\hline Unmarried & 131(19.4) & $72.61 \pm 14.08$ & $31.42 \pm 6.54$ & $41.19 \pm 9.45$ & $61.28 \pm 12.78$ & $4.01 \pm 2.86$ \\
\hline Married & $543(80.6)$ & $75.03 \pm 13.39$ & $32.83 \pm 7.31$ & $42.20 \pm 8.14$ & $64.78 \pm 12.87$ & $3.18 \pm 2.17$ \\
\hline \multicolumn{7}{|c|}{ Monthly family income (RMB) } \\
\hline$<5000$ & $234(34.7)$ & $73.22 \pm 13.49$ & $31.66 \pm 7.09$ & $41.56 \pm 8.53$ & $61.14 \pm 11.86$ & $3.32 \pm 2.26$ \\
\hline $5000-10,000$ & $281(41.7)$ & $73.49 \pm 13.23$ & $32.46 \pm 7.07$ & $41.03 \pm 8.14$ & $63.54 \pm 10.91$ & $3.62 \pm 2.54$ \\
\hline$>10,000$ & 159(23.6) & $78.42 \pm 13.53$ & $34.04 \pm 7.32$ & $44.38 \pm 8.31$ & $69.43 \pm 15.82$ & $2.89 \pm 2.04$ \\
\hline \multicolumn{7}{|l|}{ Self-rated health } \\
\hline Poor & $77(11.4)$ & $66.61 \pm 12.02$ & $30.10 \pm 5.21$ & $36.51 \pm 8.87$ & $58.44 \pm 11.47$ & $6.27 \pm 3.35$ \\
\hline Moderate & $219(32.5)$ & $70.89 \pm 12.44$ & $31.28 \pm 6.84$ & $39.61 \pm 7.75$ & $60.13 \pm 10.43$ & $3.75 \pm 1.98$ \\
\hline Good & $378(56.1)$ & $78.30 \pm 13.20$ & $33.79 \pm 7.48$ & $44.52 \pm 7.74$ & $67.55 \pm 13.45$ & $2.51 \pm 1.65$ \\
\hline
\end{tabular}

Note: $R M B$ Renminbi

Table 2 Correlations (r) between social capital, health-promoting lifestyles, and frailty $(N=674)$

\begin{tabular}{|c|c|c|c|c|c|c|c|c|c|}
\hline Variables & Mean \pm SD & 1 & 2 & 3 & 4 & 5 & 6 & 7 & 8 \\
\hline 1. Social capital & $74.56 \pm 13.55$ & 1 & & & & & & & \\
\hline 2. Structural social capital & $32.55 \pm 7.18$ & $0.844^{* * *}$ & 1 & & & & & & \\
\hline 3. Cognitive social capital & $42.01 \pm 8.41$ & $0.889^{* * *}$ & $0.506^{* * *}$ & 1 & & & & & \\
\hline 4. Health-promoting lifestyles & $64.10 \pm 12.92$ & $0.548^{* * *}$ & $0.434^{* * *}$ & $0.513^{* * *}$ & 1 & & & & \\
\hline 5. Frailty & $3.34 \pm 2.35$ & $-0.333^{* * *}$ & $-0.196^{* * *}$ & $-0.370^{* * *}$ & $-0.313^{* * *}$ & 1 & & & \\
\hline 6. Physical frailty & $1.62 \pm 1.04$ & $-0.234^{* * *}$ & $-0.135^{* * *}$ & $-0.262^{* * *}$ & $-0.242^{* * *}$ & $0.864^{* * *}$ & 1 & & \\
\hline 7. Psychological frailty & $1.14 \pm 1.03$ & $-0.285^{* * *}$ & $-0.170^{* * *}$ & $-0.314^{* * *}$ & $-0.283^{* * *}$ & $0.700^{* * *}$ & $0.319^{* * *}$ & 1 & \\
\hline 8. Social frailty & $1.16 \pm 0.55$ & $-0.197^{* * *}$ & $-0.118^{* *}$ & $-0.216^{* * *}$ & $-0.090^{*}$ & $0.401^{* * *}$ & $0.135^{* * *}$ & $0.165^{* * *}$ & 1 \\
\hline
\end{tabular}

Note: ${ }^{*} p<0.05,{ }^{* *} p<0.01,{ }^{* * *} p<0.001$

negatively associated with frailty and its three dimensions (physical, psychological, and social frailty). In other words, individuals with higher trust, cohesion, and reciprocity were less likely to suffer from frailty. This result partially confirmed Hypothesis 1, and the result was similar to that of a previous study [29]. Longitudinal studies in Japan have found that older adults who reverse the frailty process have a higher degree of trust in 
Table 3 Linear regression analysis for the association between social capital and frailty $(N=674)$

\begin{tabular}{|c|c|c|c|c|c|c|c|c|c|c|c|c|}
\hline \multirow[t]{2}{*}{ Variables } & \multicolumn{3}{|l|}{ Frailty } & \multicolumn{3}{|c|}{ Physical frailty } & \multicolumn{3}{|c|}{ Psychological frailty } & \multicolumn{3}{|c|}{ Social frailty } \\
\hline & Beta & $t$ & $P$ & Beta & $t$ & $P$ & Beta & $t$ & $P$ & Beta & $t$ & $P$ \\
\hline Age & 0.057 & 1.779 & 0.076 & 0.113 & 3.382 & 0.001 & -0.043 & -1.186 & 0.236 & -0.008 & -0.220 & 0.826 \\
\hline Sex & 0.015 & 0.474 & 0.635 & 0.063 & 1.849 & 0.065 & -0.081 & -2.187 & 0.029 & 0.033 & 0.864 & 0.388 \\
\hline Residence & -0.288 & -7.833 & $<0.001$ & -0.304 & -7.959 & $<0.001$ & -0.151 & -3.614 & $<0.001$ & -0.045 & -1.042 & 0.298 \\
\hline Education level & -0.100 & -2.762 & 0.006 & -0.098 & -2.593 & 0.010 & -0.091 & -2.194 & 0.029 & 0.032 & 0.739 & 0.460 \\
\hline Marital status & -0.075 & -2.357 & 0.019 & -0.029 & -0.893 & 0.372 & $<0.001$ & 0.005 & 0.996 & -0.232 & -6.179 & $<0.001$ \\
\hline Monthly family income & -0.030 & -0.912 & 0.362 & 0.008 & 0.243 & 0.808 & -0.062 & -1.652 & 0.099 & -0.036 & -0.927 & 0.354 \\
\hline Self-rated health & -0.347 & -10.059 & $<0.001$ & -0.340 & -9.452 & $<0.001$ & -0.208 & -5.286 & $<0.001$ & -0.089 & -2.165 & 0.031 \\
\hline Structural social capital & 0.017 & 0.464 & 0.643 & 0.019 & 0.501 & 0.616 & 0.004 & 0.107 & 0.915 & 0.008 & 0.177 & 0.859 \\
\hline Cognitive social capital & -0.226 & -6.034 & $<0.001$ & -0.128 & -3.269 & 0.001 & -0.220 & -5.153 & $<0.001$ & -0.175 & -3.942 & $<0.001$ \\
\hline$R^{2}$ & 0.369 & & & 0.317 & & & 0.178 & & & 0.113 & & \\
\hline$F$ & $43.056^{* * *}$ & & & $34.197^{* * *}$ & & & $16.026^{* * *}$ & & & $9.406^{* * *}$ & & \\
\hline
\end{tabular}

Note: ${ }^{* *} p<0.001$, beta $=$ standardized regression coefficients, $R^{2}=$ coefficient of determination

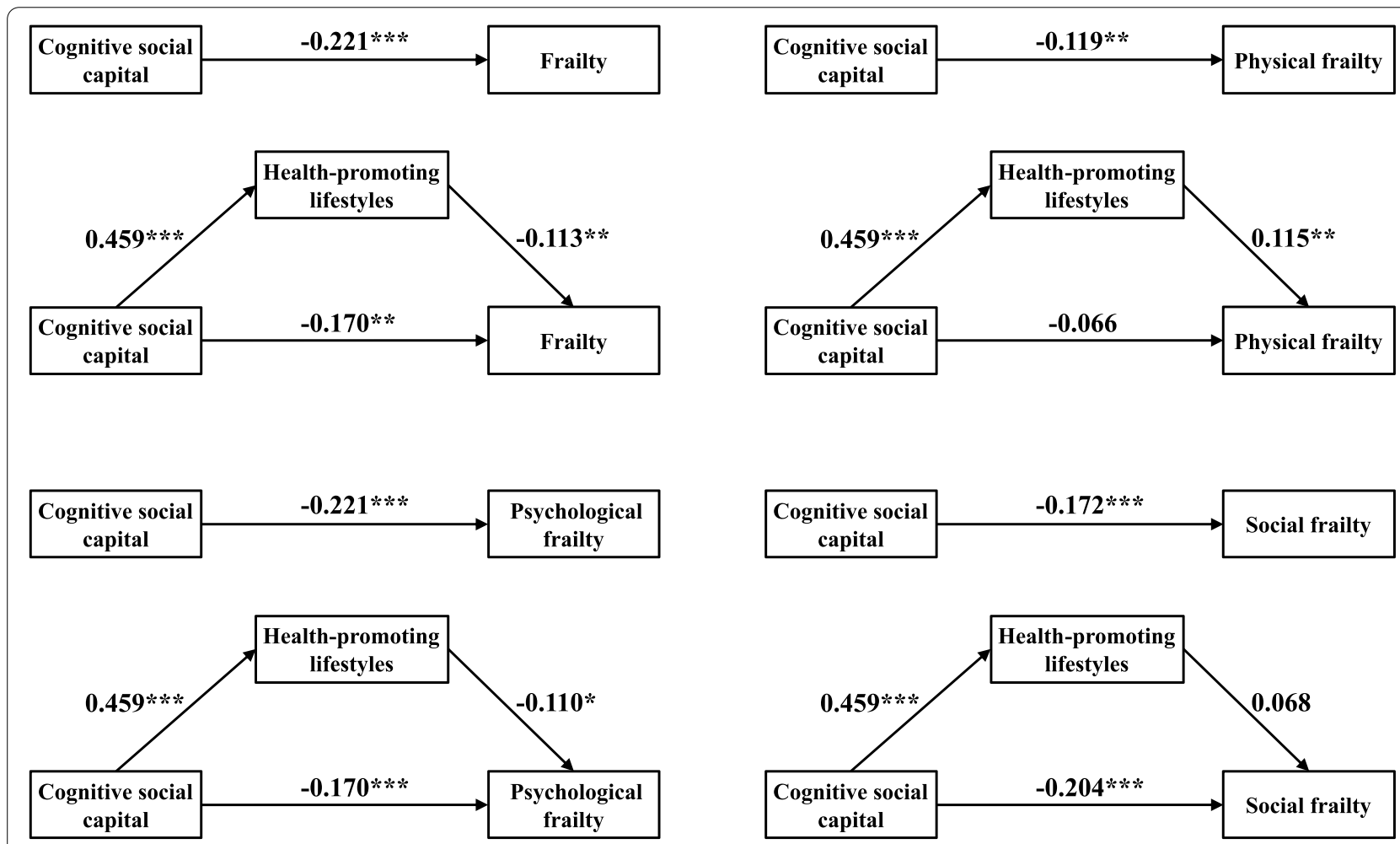

Fig. 2 Health-promoting lifestyles mediated the association of cognitive social capital with frailty, physical frailty, psychological frailty, and social frailty. Note: ${ }^{* *} p<0.01,{ }^{* * *} p<0.001$

their neighbors and have closer relationships with them, which may assist in maintaining and promoting older adults' physical, psychological and social functions [29]. In addition, a previous study also revealed that greater social cohesion can prevent frailty among older adults in the community [54]. Social cohesion is the result of a complex process involving factors such as the quality of the neighborhood, the individual's mental and physical condition, the individual's subjective assessment of the community, and the nature and quality of social contacts [55]. A more cohesive society may be more likely to organize various activities, such as health education 
Table 4 Testing the Mediation effect of health-promoting lifestyles

\begin{tabular}{|c|c|c|c|c|c|}
\hline Path & Effect & Beta & $S E$ & $95 \% \mathrm{Cl}$ & $P$ \\
\hline \multirow{4}{*}{$\begin{array}{l}\text { Cognitive social capital } \rightarrow \text { health-promoting lifestyles } \\
\rightarrow \text { frailty }\end{array}$} & Total effect, c & -0.221 & 0.037 & $-0.292 \sim-0.146$ & $<0.001$ \\
\hline & Direct effect, $c^{\prime}$ & -0.170 & 0.042 & $-0.252 \sim-0.091$ & $<0.001$ \\
\hline & Indirect effect, $a^{*} b$ & -0.052 & 0.016 & $-0.084 \sim-0.019$ & 0.002 \\
\hline & Ratio of indirect to total effect mediated ( $\left.a^{*} b / c\right)$ & $23.5 \%$ & & & \\
\hline \multirow{4}{*}{$\begin{array}{l}\text { Cognitive social capital } \rightarrow \text { health-promoting lifestyles } \\
\rightarrow \text { physical frailty }\end{array}$} & Total effect, c & -0.119 & 0.039 & $-0.194 \sim-0.040$ & 0.005 \\
\hline & Direct effect, $c^{\prime}$ & -0.066 & 0.044 & $-0.152 \sim 0.019$ & 0.123 \\
\hline & Indirect effect, $a^{*} b$ & -0.053 & 0.017 & $-0.086 \sim-0.020$ & 0.002 \\
\hline & Ratio of indirect to total effect mediated ( $\left.a^{*} b / c\right)$ & $44.5 \%$ & & & \\
\hline \multirow{4}{*}{$\begin{array}{l}\text { Cognitive social capital } \rightarrow \text { health-promoting lifestyles } \\
\rightarrow \text { psychological frailty }\end{array}$} & Total effect, c & -0.221 & 0.037 & $-0.293 \sim-0.150$ & $<0.001$ \\
\hline & Direct effect, $c^{\prime}$ & -0.170 & 0.042 & $-0.257 \sim-0.090$ & $<0.001$ \\
\hline & Indirect effect, $a^{*} b$ & -0.051 & 0.019 & $-0.090 \sim-0.012$ & 0.010 \\
\hline & Ratio of indirect to total effect mediated ( $\left.a^{*} b / c\right)$ & $23.1 \%$ & & & \\
\hline \multirow{4}{*}{$\begin{array}{l}\text { Cognitive social capital } \rightarrow \text { health-promoting lifestyles } \\
\rightarrow \text { social frailty }\end{array}$} & Total effect, c & -0.172 & 0.043 & $-0.251 \sim-0.084$ & $<0.001$ \\
\hline & Direct effect, $c^{\prime}$ & -0.204 & 0.049 & $-0.297 \sim-0.107$ & $<0.001$ \\
\hline & Indirect effect, $a^{*} b$ & 0.031 & 0.020 & $-0.005 \sim 0.072$ & 0.096 \\
\hline & Ratio of indirect to total effect mediated ( $\left.a^{*} \mathrm{~b} / \mathrm{c}\right)$ & NA & & & \\
\hline
\end{tabular}

Note: beta standardized coefficient, $C I$ confidence interval, SE standardized error, NA not applicable

and physical exercise, to provide residents with more opportunities to maintain and promote health [56]. This implies that individuals who perceive greater cohesion may be more willing to participate in such activities. In this process, physical fitness is strengthened and psychological and social needs are met, resulting in the possibility of frailty being reduced. Reciprocity refers to the ability to give something in return for receiving, and embodies mutual help and support between individuals [57]. A previous study found that recognizing the norms of reciprocity can prevent or reduce the loss of frail older adults' own resources, thereby promoting their health [58]. In addition, reciprocity can encourage individuals to participate in voluntary services and sports activities [59], and promote the dissemination of health information [60], all of which are beneficial for reducing frailty in older adults.

However, inconsistent with the results of previous studies that indicated that social activities influenced frailty [29], the relationship between structural social capital and frailty was not statistically significant. A previous study has suggested that links between social structure and health largely depend on the quality of selfexperience in the individual's life [61]. In other words, if individuals with higher structural social capital do not have good cognition and experience of the social environment, they still cannot use those social resources to benefit their health. Previous studies have also suggested that structural social capital and cognitive social capital have different effects on health outcomes [62]. This is mainly reflected in the fact that structural social capital affects health through participation in social activities [63], while cognitive social capital does this through controlling risky behaviors, reducing stress and providing mutual assistance and support $[64,65]$. In addition, previous studies also suggested that cognitive social capital is a stronger protective factor for depressive symptoms than structural social capital, and cognitive social capital mediates the relationship between structural social capital and depressive symptoms. It may be inferred from this that the relationship between structural social capital and frailty may be hidden by cognitive social capital. In view of the lack of relevant research evidence, further exploration is needed in this regard.

This study also found that health-promoting lifestyles mediated the associations of cognitive social capital with frailty, and the physical and psychological frailty dimensions. This study preliminarily elucidated the mechanism of association between cognitive social capital and frailty, and provided a scientific basis for further targeted intervention. This mediating effect was mainly divided into two stages, namely, 1) cognitive social capital had a positive impact on health-promoting lifestyles, and 2) health-promoting lifestyles had a negative impact on frailty. Both of these stages have been confirmed in previous studies [40,66-68], which provides sufficient literature support for this study. Individuals with higher cognitive social capital have a stronger sense of social identity and closer neighborhood relationships, that enable them to encourage each other to cultivate a healthy lifestyle [69], and the improvement of lifestyle promotes physical and 
psychological health [70], resulting in a lower risk of frailty. It is worth noting that there was no statistically significant association between the health-promoting lifestyles and the social frailty dimension, that led to the failure of the mediation effect. This may have been because the measurement content of social frailty in this study was whether participants lived alone, their desire for others' company and whether they received help from others. Logically speaking, whether individuals adopted a healthy lifestyle did not appear to affect their social frailty in this study. This result lacks literary support, and further exploration is necessary in the future.

This study has important scientific and practical significance for the prevention and intervention of frailty. First, this study supplements the literature elucidating the association between social capital and frailty in older adults. Second, to our best knowledge, this is the first study to explore the mediating of health-promoting lifestyles in the association between the social capital and frailty. It presents novel discovery on the mediating mechanism underpinning the association between the social capital and frailty among older adults. Third, this study can provide new ideas for the prevention and intervention of frailty. Findings of this study suggest that in the future, we can implement interventions on frailty from the perspective of cognitive social capital and health-promoting lifestyles. Chinese community health care workers can consider formulating community frailty intervention plans. On the one hand, they can enhance the cognitive social capital of the older adults by organizing collective health-related activities and building community mutual assistance platforms. On the other hand, they can strengthen health education and guide the older adults to develop healthy lifestyles such as physical exercise and reasonable diet, thereby reducing the occurrence of frailty.

This study has some limitations. First, our research is cross-sectional, which makes it impossible to clarify the causal relationship and the direction of effect among social capital, health-promoting lifestyles, and frailty. In the future, longitudinal studies or intervention studies can be conducted to further confirm the longitudinal association or causality between them. Second, the social capital assessment tool used in this study is different from previous research, so we need to be cautious about the comparison of study results with previous study results. In the future, the same assessment tools as this study can be used to further verify the results of this study. Third, all surveys were self-reported, and that may have introduced information bias. Finally, our sample was only selected from one city in China, so the research results may not be generalizable to older adults in other countries and regions.

\section{Conclusions}

Higher cognitive social capital was associated with a reduced likelihood of frailty. The health-promoting lifestyles partially mediated the association between cognitive social capital and frailty. The use of health-promoting lifestyles or appropriate cognitive social capital interventions may reduce frailty among older adults.

\section{Abbreviations}

CSSCS: Chinese Shortened Social Capital Scale; HPLP-S: Simplified version of the Health-Promoting Lifestyle Profile; TFI: Tilburg Frailty Indicator; SD: Standard Deviation; SEM: Structural Equation Models; Cl: Confidence Interval; RMB: Renminbi.

\section{Supplementary Information}

The online version contains supplementary material available at https://doi. org/10.1186/s12877-022-02815-z.

Additional file 1. Demographic information questionnaire.

Acknowledgements

Thank all participants recruited in this study.

Authors' contributions

S.H. and S.L. designed the study and collected data. S.L. conducted the statistical analyses. S.H. wrote the original draft; C.J. and S.L. revised original draft. All authors have read and approved the manuscript.

\section{Funding}

Not applicable.

\section{Availability of data and materials}

The datasets can be made available to any interested person(s) contacting the corresponding author via email.

\section{Declarations}

Ethics approval and consent to participate

All participants signed an informed consent form before the survey. This study has been approved by the Medical Ethics Committee of Xiangya School of Public Health, Central South University (identification code: XYGW-2020-101).

\section{Consent for publication}

Not applicable.

\section{Competing interests}

The authors declare that they have no competing interests.

\section{Author details}

${ }^{1}$ Hunan Cancer Hospital, The Affiliated Cancer Hospital of Xiangya School of Medicine, Central South University, Changsha 410013, China. ${ }^{2}$ Department of Social Medicine and Health Service Management, Xiangya School of Public Health, Central South University, Changsha 410078, China.

Received: 21 August 2021 Accepted: 3 February 2022

Published online: 02 March 2022 


\section{References}

1. Ogura S, Jakovljevic MM. Editorial: global population aging - health care, social and economic consequences. Front Public Health. 2018;6:335.

2. Clegg A, Young J, lliffe S, Rikkert MO, Rockwood K. Frailty in elderly people. Lancet (London, England). 2013;381(9868):752-62.

3. Fried LP, Tangen CM, Walston J, Newman AB, Hirsch C, Gottdiener J, et al. Frailty in older adults: evidence for a phenotype. J Gerontol A Biol Sci Med Sci. 2001;56(3):M146-56.

4. Vermeiren S, Vella-Azzopardi R, Beckwée D, Habbig AK, Scafoglieri A Jansen $B$, et al. Frailty and the prediction of negative health outcomes: a Meta-analysis. J Am Med Dir Assoc. 2016;17(12):1163.e1161-17.

5. Kojima G, Iliffe S, Walters K. Frailty index as a predictor of mortality: a systematic review and meta-analysis. Age Ageing. 2018;47(2):193-200.

6. Kojima G. Frailty as a predictor of hospitalisation among communitydwelling older people: a systematic review and meta-analysis. J Epidemiol Community Health. 2016;70(7):722-9.

7. Kojima G. Frailty as a predictor of disabilities among community-dwelling older people: a systematic review and meta-analysis. Disabil Rehabil. 2017;39(19):1897-908.

8. Kojima G. Frailty as a predictor of future falls among community-dwelling older people: a systematic review and Meta-analysis. J Am Med Dir Assoc. 2015;16(12):1027-33

9. Kojima G. Frailty as a predictor of fractures among communitydwelling older people: a systematic review and meta-analysis. Bone. 2016;90:116-22.

10. Kojima G, Taniguchi Y, Iliffe S, Walters K. Frailty as a predictor of Alzheimer disease, vascular dementia, and all dementia among community-dwelling older people: a systematic review and Meta-analysis. J Am Med Dir Assoc. 2016;17(10):881-8.

11. Ofori-Asenso R, Chin KL, Mazidi M, Zomer E, llomaki J, Zullo AR, et al. Global incidence of frailty and Prefrailty among community-dwelling older adults: a systematic review and Meta-analysis. JAMA Netw Open. 2019;2(8):e198398.

12. Siriwardhana DD, Hardoon S, Rait G, Weerasinghe MC, Walters KR. Prevalence of frailty and prefrailty among community-dwelling older adults in low-income and middle-income countries: a systematic review and meta-analysis. BMJ Open. 2018;8(3):e018195

13. Feng Z, Lugtenberg M, Franse C, Fang X, Hu S, Jin C, et al. Risk factors and protective factors associated with incident or increase of frailty among community-dwelling older adults: a systematic review of longitudinal studies. PLoS One. 2017;12(6):e0178383.

14. Cardoso AL, Fernandes A, Aguilar-Pimentel JA, de Angelis MH, Guedes $J R$, Brito MA, et al. Towards frailty biomarkers: candidates from genes and pathways regulated in aging and age-related diseases. Ageing Res Rev. 2018:47:214-77.

15. Ferrucci L, Fabbri E. Inflammageing: chronic inflammation in ageing, cardiovascular disease, and frailty. Nat Rev Cardiol. 2018;15(9):505-22.

16. Xu L, Zhang J, Shen S, Hong X, Zeng X, Yang Y, et al. Association between body composition and frailty in elder inpatients. Clin Interv Aging. 2020;15:313-20

17. Lorenzo-López L, Maseda A, de Labra C, Regueiro-Folgueira L, RodríguezVillamil JL, Millán-Calenti JC. Nutritional determinants of frailty in older adults: a systematic review. BMC Geriatr. 2017:17(1):108

18. Weiss CO. Frailty and chronic diseases in older adults. Clin Geriatr Med 2011:27(1):39-52.

19. Kehler DS, Theou O. The impact of physical activity and sedentary behaviors on frailty levels. Mech Ageing Dev. 2019;180:29-41.

20. Kojima G, Avgerinou C, Iliffe S, Jivraj S, Sekiguchi K, Walters K. Fruit and vegetable consumption and frailty: a systematic review. J Nutr Health Aging. 2018;22(8):1010-7.

21. Kim J, Lee Y, Won CW, Kim MK, Kye S, Shim JS, et al. Dietary patterns and frailty in older Korean adults: results from the Korean frailty and aging cohort study. Nutrients. 2021;13(2):601.

22. Desrichard $O$, Vallet F, Agrigoroaei S, Fagot D, Spini D. Frailty in aging and its influence on perceived stress exposure and stress-related symptoms: evidence from the Swiss vivre/Leben/Vivere study. Eur J Ageing 2018;15(4):331-8

23. Soysal P, Veronese N, Thompson T, Kahl KG, Fernandes BS, Prina AM, et al. Relationship between depression and frailty in older adults: a systematic review and meta-analysis. Ageing Res Rev. 2017;36:78-87.
24. Gordon SJ, Baker N, Kidd M, Maeder A, Grimmer KA. Pre-frailty factors in community-dwelling 40-75 year olds: opportunities for successful ageing. BMC Geriatr. 2020;20(1):96.

25. Gale CR, Westbury L, Cooper C. Social isolation and loneliness as risk factors for the progression of frailty: the English longitudinal study of ageing. Age Ageing. 2018;47(3):392-7

26. Klinpudtan N, Kabayama M, Gondo Y, Masui Y, Akagi Y, Srithumsuk W, et al. Association between heart diseases, social factors and physical frailty in community-dwelling older populations: the septuagenarians, octogenarians, nonagenarians investigation with centenarians study. Geriatr Gerontol Int. 2020;20(10):974-9.

27. de Labra C, Maseda A, Lorenzo-López L, López-López R, Buján A, Rodríguez-Villamil JL, et al. Social factors and quality of life aspects on frailty syndrome in community-dwelling older adults: the VERISAÚDE study. BMC Geriatr. 2018;18(1):66.

28. Jung $H$, Kim M, Lee $Y$, Won CW. Prevalence of physical frailty and its multidimensional risk factors in Korean community-dwelling older adults: findings from Korean frailty and aging cohort study. Int J Environ Res Public Health. 2020;17(21):7883.

29. Takatori K, Matsumoto D. Social factors associated with reversing frailty progression in community-dwelling late-stage elderly people: an observational study. PLoS One. 2021;16(3):e0247296.

30. Kawachi I, Subramanian SV, Kim D. Social Capital and Health. In: Kawachi I, Subramanian SV, Kim D, editors. Social Capital and Health. New York: Springer New York; 2008. p. 1-26.

31. Leonardi R, Nanetti RY, Putnam RD. Making democracy work: civic traditions in modern Italy. Princeton: Princeton University Press; 2001.

32. Duh-Leong C, Dreyer BP, Huang TT, Katzow M, Gross RS, Fierman AH, et al. Social capital as a positive social determinant of health: a narrative review. Acad Pediatr. 2021;21(4):594-9.

33. Rodgers J, Valuev AV, Hswen Y, Subramanian SV. Social capital and physical health: an updated review of the literature for 2007-2018. Soc Sci Med. 2019:236:112360

34. Nyqvist F, Forsman AK, Giuntoli G, Cattan M. Social capital as a resource for mental well-being in older people: a systematic review. Aging Ment Health. 2013:17(4):394-410.

35. Coll-Planas L, Nyqvist F, Puig T, Urrútia G, Solà I, Monteserín R. Social capital interventions targeting older people and their impact on health: a systematic review. J Epidemiol Community Health. 2017;71(7):663-72.

36. Jarach CM, Cesari M. Frailty beyond the clinical dimension: discussion about the underlying aspect of the social capital. Minerva Med. 2018;109(6):472-8

37. Braveman P, Egerter S, Williams DR. The social determinants of health: coming of age. Annu Rev Public Health. 2011;32:381-98.

38. Cockerham WC, Hamby BW, Oates GR. The social determinants of chronic disease. Am J Prev Med. 2017:52(1s1):S5-s12.

39. Xue $X$, Cheng M. Social capital and health in China: exploring the mediating role of lifestyle. BMC Public Health. 2017;17(1):863.

40. Cui GH, Li SJ, Yin YT, Chen LJ, Li JQ, Liang FY, et al. The relationship among social capital, eHealth literacy and health behaviours in Chinese elderly people: a cross-sectional study. BMC Public Health. 2021;21(1):45.

41. Brinkman S, Voortman T, Kiefte-de Jong JC, van Rooij FJA, Ikram MA, Rivadeneira F, et al. The association between lifestyle and overall health, using the frailty index. Arch Gerontol Geriatr. 2018;76:85-91.

42. Hajian-Tilaki K. Sample size estimation in epidemiologic studies. Caspian Intern Med. 2011;2(4):289-98.

43. Tian P, Yang N, Hao Q, Peng C. Epidemiological of frailty in Chinese elderly population: a systematic review. Chin J Evid Based Med. 2019;19(3):656-64.

44. Bai Z, Wang Z, Shao T, Qin X, Hu Z. Association between social capital and loneliness among older adults: a cross-sectional study in Anhui Province, China. BMC Geriatr. 2021;21(1):26.

45. Bai Z, Xu Z, Xu X, Qin X, Hu W, Hu Z. Association between social capital and depression among older people: evidence from Anhui Province, China. BMC Public Health. 2020;20(1):1560

46. Walker SN, Sechrist KR, Pender NJ. The health-promoting lifestyle profile: development and psychometric characteristics. Nurs Res. 1987;36(2):76-81.

47. Huang $\mathrm{YH}$, Chiou CJ. Assessment of the health-promoting lifestyle profile on reliability and validity. Kaohsiung J Med Sci. 1996;12(9):529-37. 
48. Wei M-H, Lu C-M. Development of the short-form Chinese health-promoting lifestyle profile. J Health Educ. 2005;24:25-46.

49. Gobbens RJ, Uchmanowicz I. Assessing frailty with the Tilburg frailty Indicator (TFI): a review of reliability and validity. Clin Interv Aging. 2021;16:863-75.

50. Gobbens RJ, van Assen MA, Luijkx KG, Wijnen-Sponselee MT, Schols JM. The Tilburg frailty Indicator: psychometric properties. J Am Med Dir Assoc. 2010;11(5):344-55.

51. Dong L, Liu N, Tian X, Qiao X, Gobbens RJJ, Kane RL, et al. Reliability and validity of the Tilburg frailty Indicator (TFI) among Chinese communitydwelling older people. Arch Gerontol Geriatr. 2017;73:21-8.

52. MacKinnon DP, Fairchild AJ, Fritz MS. Mediation analysis. Annu Rev Psychol. 2006;58(1):593-614.

53. Carrión GC, Nitzl C, Roldán JL. Mediation analyses in partial least squares structural equation modeling: guidelines and empirical examples. In: Latan H, Noonan R, editors. Partial least squares path modeling: basic concepts, methodological issues and applications. Cham: Springer International Publishing; 2017. p. 173-95.

54. Cramm JM, Nieboer AP. Relationships between frailty, neighborhood security, social cohesion and sense of belonging among communitydwelling older people. Geriatr Gerontol Int. 2013;13(3):759-63.

55. Gory ML, Ward R, Sherman S. The ecology of aging: neighborhood satisfaction in an older population. Sociol Q. 1985;26(3):405-18.

56. Cohen DA, Finch BK, Bower A, Sastry N. Collective efficacy and obesity: the potential influence of social factors on health. Soc Sci Med. 2006;62(3):769-78.

57. Gouldner A. The NORM of reciprocity: a preliminary statement * Am Sociol Rev. 1960;25:161-78.

58. Vernooij-Dassen M, Leatherman S, Rikkert MO. Quality of care in frail older people: the fragile balance between receiving and giving. BMJ (Clinical research ed). 2011;342:d403.

59. Wang R, Chen H, Liu Y, Lu Y, Yao Y. Neighborhood social reciprocity and mental health among older adults in China: the mediating effects of physical activity, social interaction, and volunteering. BMC Public Health. 2019:19(1):1036.

60. de Wit L, Fenenga C, Giammarchi C, di Furia L, Hutter I, de Winter A, et al. Community-based initiatives improving critical health literacy: a systematic review and meta-synthesis of qualitative evidence. BMC Public Health. 2017;18(1):40.

61. Siegrist J. Social reciprocity and health: new scientific evidence and policy implications. Psychoneuroendocrinology. 2005;30(10):1033-8.

62. Giordano GN, Ohlsson H, Lindström M. Social capital and health—purely a question of context? Health Place. 2011;17(4):946-53.

63. Berkman LF, Syme SL. Social networks, host resistance, and mortality: a nine-year follow-up study of Alameda County residents. Am J Epidemiol. 1979;109(2):186-204.

64. Giordano GN, Lindstrom M. The impact of changes in different aspects of social capital and material conditions on self-rated health over time: a longitudinal cohort study. Soc Sci Med. 2010;70(5):700-10.

65. Islam MK, Merlo J, Kawachi I, Lindström M, Gerdtham U-G. Social capital and health: does egalitarianism matter? A literature review. Int J Equity Health. 2006;5(1):3.

66. Chen W-L, Zhang C-G, Cui Z-Y, Wang J-Y, Zhao J, Wang J-W, et al. The impact of social capital on physical activity and nutrition in China: the mediating effect of health literacy. BMC Public Health. 2019;19(1):1-10.

67. Barreto PD, Rolland Y, Maltais M, Vellas B, Grp MS. Associations of multidomain lifestyle intervention with frailty: secondary analysis of a randomized controlled trial. Am J Med. 2018;131(11):1382.e7-1382.e13.

68. Poli S, Cella A, Puntoni M, Musacchio C, Pomata M, Torriglia D, et al. Frailty is associated with socioeconomic and lifestyle factors in communitydwelling older subjects. Aging Clin Exp Res. 2017;29(4):721-8.

69. Lindström M. Social Capital and Health-Related Behaviors. In: Kawachi I, Subramanian SV, Kim D, editors. Social Capital and Health. New York: Springer New York; 2008. p. 215-38.

70. Wang J, Geng L. Effects of socioeconomic status on physical and psychological health: lifestyle as a mediator. Int J Environ Res Public Health. 2019;16(2):281.

\section{Publisher's Note}

Springer Nature remains neutral with regard to jurisdictional claims in published maps and institutional affiliations.
Ready to submit your research? Choose BMC and benefit from:

- fast, convenient online submission

- thorough peer review by experienced researchers in your field

- rapid publication on acceptance

- support for research data, including large and complex data types

- gold Open Access which fosters wider collaboration and increased citations

- maximum visibility for your research: over $100 \mathrm{M}$ website views per year

At BMC, research is always in progress.

Learn more biomedcentral.com/submissions 